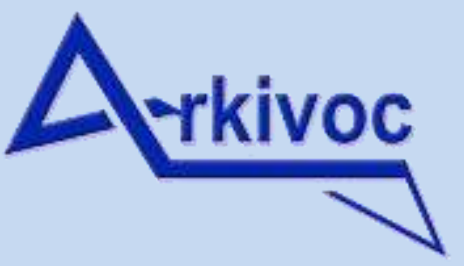

Free to Authors and Readers
A Platinum Open Access Journal for Organic Chemistry
Paper

Arkivoc 2021, part v, 97-109

DOAJ Seal

\title{
Synthesis and characterization of fluorescent amino acid dimethylaminoacridonylalanine
}

\author{
Chloe M. Jones, ${ }^{\mathrm{a}, \mathrm{b}}$ George A. Petersson, ${ }^{\mathrm{c}}$ and E. James Petersson ${ }^{\mathrm{a}}$ \\ ${ }^{a}$ Department of Chemistry; University of Pennsylvania; 231 South 34th Street; Philadelphia, Pennsylvania \\ 19104-6323, USA \\ ${ }^{b}$ Biochemistry and Molecular Biophysics Graduate Group; University of Pennsylvania; 3700 Hamilton Walk, \\ Philadelphia, PA 19104, USA \\ 'Temple University Institute for Computational Molecular Science, 1925 N. 12th Street, Philadelphia, PA 19122, \\ USA \\ Email: ejpetersson@sas.upenn.edu
}

We are pleased to dedicate this article to Prof. Peter A. Jacobi, longtime colleague of George A. Petersson at Wesleyan University and teacher of E. James Petersson at Dartmouth College.

Received 02-22-2021

Accepted 03-27-2021

Published on line 04-05-2021

\section{Abstract}

Fluorescent amino acids are powerful biophysical tools as they can be used in structural or imaging studies of a given protein without significantly perturbing its native fold or function. Here, we have synthesized and characterized 7-(dimethylamino)acridon-2-ylalanine (Dad), a red-shifted derivative of the geneticallyincorporable amino acid, acridon-2-ylalanine. Alkylation increases the quantum yield and fluorescence lifetime of Dad relative to a previously published amino acid, 7-aminoacridon-2-ylalanine (Aad). These properties of Dad make it a potentially valuable protein label, and we have performed initial testing of its ability to be genetically incorporated using an evolved aminoacyl tRNA synthetase.
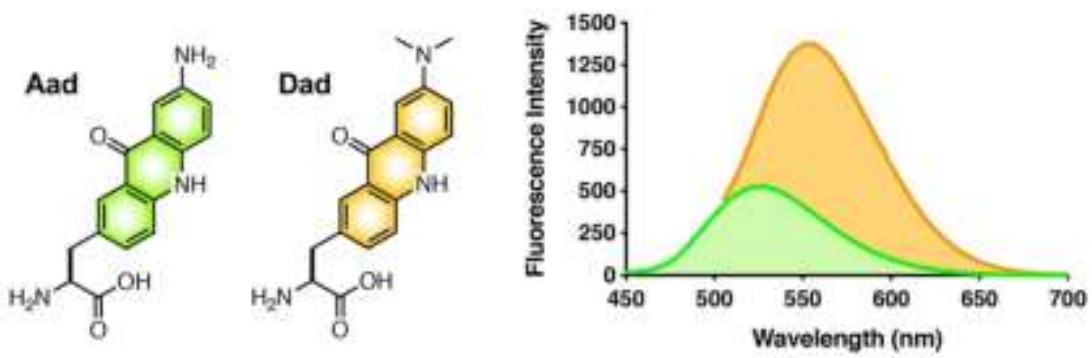

Keywords: Fluorescence, unnatural amino acid, acridone, twisted intramolecular charge transfer 


\section{Introduction}

Small fluorescent molecules can be designed to provide real-time information on a variety of biological processes, including the structure, function, and localization of proteins. ${ }^{1-3}$ Fluorescent unnatural amino acids (Uaas) are particularly valuable as they provide a minimally perturbing way to label proteins without disturbing their nascent structure and function..$^{4-6}$ Proteins labeled with fluorescent Uaas can be used in microscopy experiments as well as a variety of biophysical experiments (Figure 1). These include fluorescence polarization (FP) assays, which monitor changes in the rotational dynamics of the fluorophore, where polarization of the emitted light typically correlates inversely with molecular size. ${ }^{7-8} \mathrm{FP}$ is often used to measure the binding of a smaller peptide or protein to a larger protein to determine binding rates or affinities. Environmental effects on fluorescent Uaa emission can be used to study conformational changes of a protein or binding to other biomolecules provided that they result in a change in the fluorophore environment. ${ }^{9}$ The effects can include changes in absorption and/or emission wavelength $(\lambda)$, extinction coefficient $(\varepsilon)$, fluorescence lifetime $(\tau)$, or quantum yield (QY) due to solvatochromic effects or quenching by nearby amino acids such as Tyr, Trp, Cys, or His. When proteins are labeled by two probes, distance changes can be studied based on interactions of the fluorescent Uaa with an appropriately matched partner through either Förster resonance energy transfer (FRET) or quenching due to photo-induced electron transfer (PeT). ${ }^{10}$ FRET requires spectral overlap of an acceptor chromophore with the donor fluorophore and PeT requires matching of donor and acceptor redox potentials. Both FRET and PeT can be used to monitor structural changes, binding events, and cleavage by proteases.
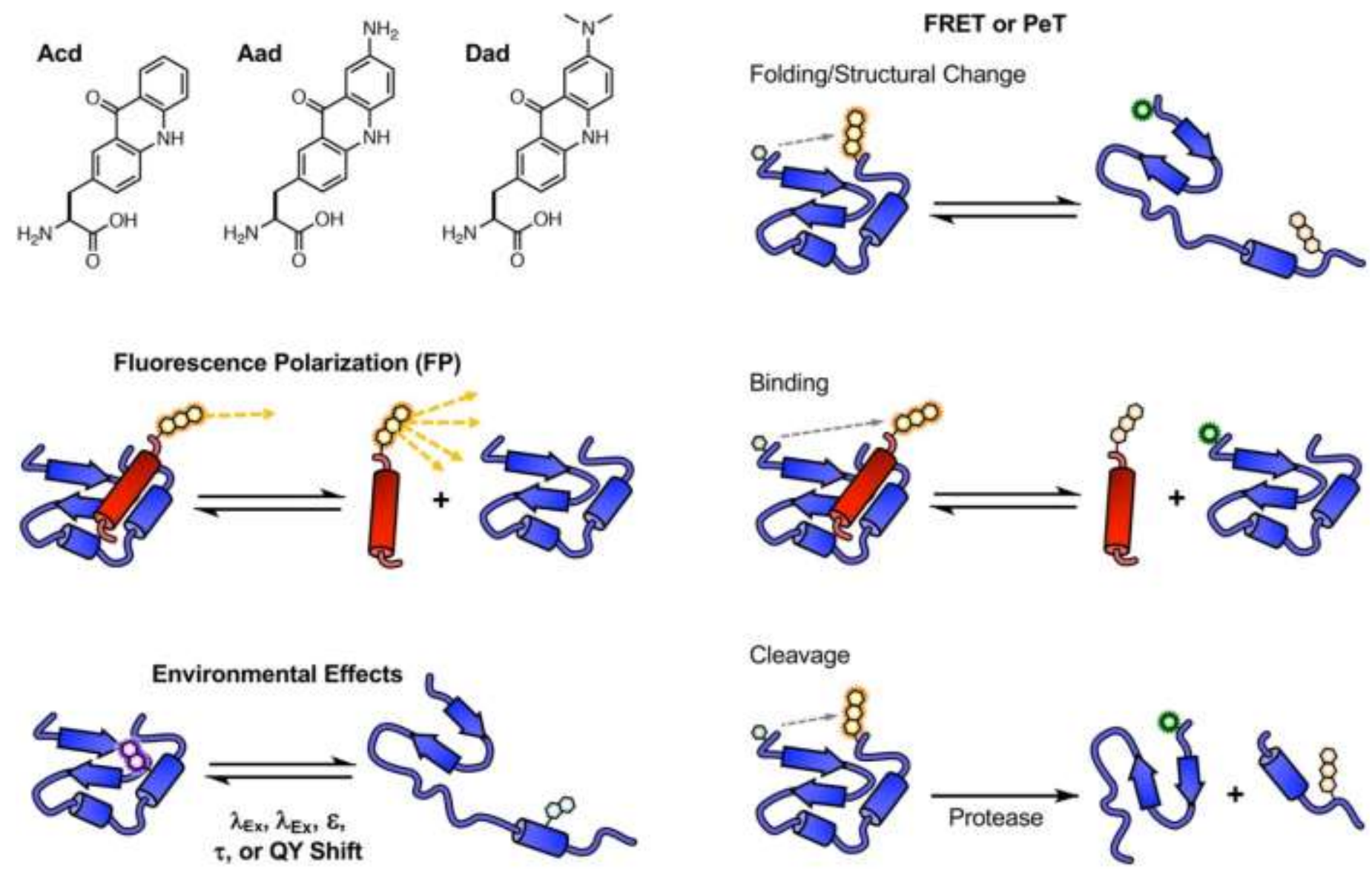

Figure 1. Protein biophysics experiments enabled by fluorescent Uaas. 
We have previously demonstrated the utility of acridon-2-ylalainne (Acd, Figure 1), a genetically incorporable fluorophore with a blue emission. ${ }^{11-18}$ Acd's high QY and long fluorescence lifetime can be valuable for biophysical studies, particularly FP where the range of protein sizes that can effectively be sensed increases with fluorophore lifetime. ${ }^{19}$ However, Acd's UV excitation and blue emission can lead to photodamage. ${ }^{20}$ We have demonstrated that derivatizing Acd can red-shift its excitation and emission, ${ }^{14}$ which we hope to further develop towards a genetically incorporable Acd derivative FRET pair. However, our best candidate to date, 7aminoacridon-2-ylalanine (Aad, Figure 1) has a low fluorescence QY. ${ }^{14}$ We hypothesized that Aad's loss in QY relative to Acd could be due to the amino group undergoing twisted intermolecular charge transfer (TICT) upon excitation. ${ }^{21}$ It has been shown that alkylation of pendant amines can reduce TICT through steric effects, increasing QY. ${ }^{22-23}$ Here, we have synthesize an alkylated Aad derivative, 7-(dimethylamino)acridon-2-ylalanine (Dad, Figure 1). We characterize its fluorescent properties and evaluate its prospects for genetic incorporation using evolved aminoacyl tRNA synthetase (aaRS) enzymes.

\section{Results and Discussion}

Dad was synthesized in five steps from tyrosine methyl ester and 2,5-aminobenzonitrile, using a route similar to the route previously employed to synthesize Acd and Aad. The key step was selective methylation of the 5amino group of 2,5-aminobenzonitrile, which was achieved using Eschweiler-Clarke methylation in $49 \%$ yield. Since there are two amines that can be readily methylated, this step relies on the precise addition of 2.5 equivalents of paraformaldehyde followed by 3.0 equivalents of sodium cyanoborohydride. While the major product of this reaction is the desired doubly methylated species, the crude mixture also contained 6\% of singly methylated material and $0.06 \%$ of triply methylated material according to liquid chromatography mass spectrometry (LC-MS) analysis. Successful methylation to form 2-amino-5-(dimethylamino)benzonitrile (1) was confirmed by examination of the aromatic peaks in the ${ }^{1} \mathrm{H}$ NMR spectrum. If methylation instead occurred at the 2-amino group, the combination of substituent effects would result in the proton at the 3 position being more shielded than the proton at the 6 position. We instead see that the protons at carbons 3 and 6 are overlapping at $\sim 6.8 \mathrm{ppm}$, consistent with previous NMR characterization of 1 by Harris et al. ${ }^{24}$ They synthesized 1 by reaction of dimethylamine with 5-chloro-2-nitrobenzonitrile to form 5-(dimethylamino)-2nitrobenzonitrile, followed by tin reduction to form 1 without ambiguity as to the position of the dimethylamino group. Notably, our yield of $49 \%$, while modest, is an improvement over their $39 \%$ yield over two steps.

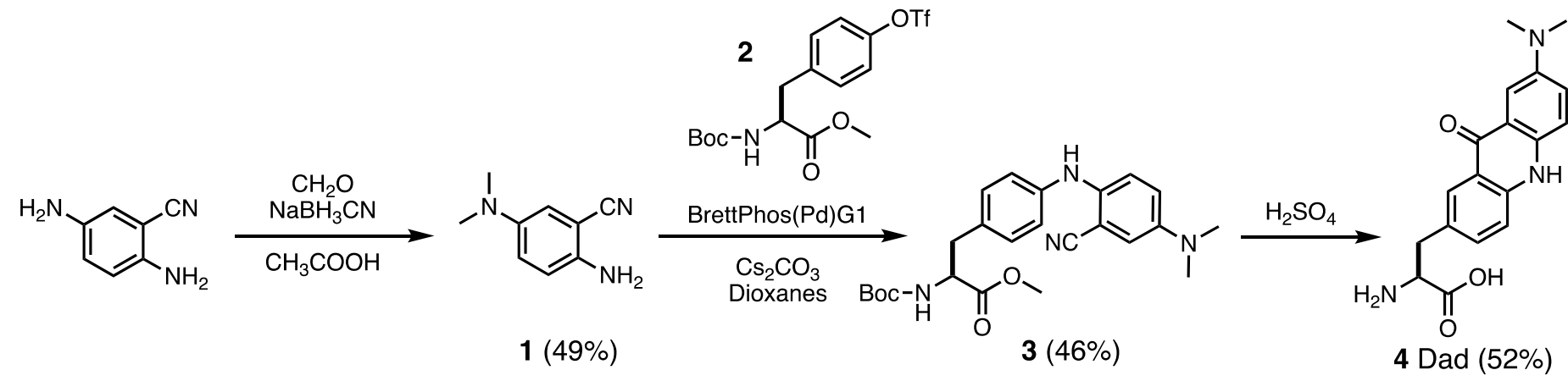

Scheme 1. Synthesis of Dad. 
Amino acid intermediate $\mathbf{3}$ was formed by Buchwald-Hartwig cross-coupling of $\mathbf{1}$ with tertbutyloxycarbonyl (Boc) protected, triflated tyrosine methyl ester 2 using BrettPhos Pd G1 and cesium carbonate. Compound $\mathbf{2}$ was synthesized from tyrosine $O$-methyl ester as previously described. ${ }^{25}$ Selective arylation of the 2-amino group of 1 was made possible by the prior methylation of the 5-amino group. Two alternative catalysts were also tested for this cross coupling step (RuPhos Pd G4 39\%, rac-BINAP+ Pd(OAc) 2 10\%), but were abandoned in favor of BrettPhos Pd G1 since they produced lower yields. The final Dad product (4) was formed by removal of the Boc and methyl ester protecting groups as well as Friedel-Crafts cyclization to form the acridone ring system by heating in sulfuric acid. After purification by reverse-phase chromatography, Dad was obtained in $52 \%$ yield ( $11 \%$ overall yield from 2,5 -aminobenzonitrile).

Spectroscopic characterization of Dad and comparison to Aad. Following Dad synthesis, we measured its absorbance spectrum, extinction coefficient $(\varepsilon)$, emission spectrum, fluorescence lifetime $(\tau)$, and QY (Figure 2, Table 1, Figures S1-6, and Table 2). These measurements were performed in a variety of solvents, including buffered aqueous solutions of varying $\mathrm{pH}$. Dad has a broad absorption centered at $430 \mathrm{~nm}$ and emission maximum of $572 \mathrm{~nm}$ in a 50:50 mixture of acetonitrile and phosphate-buffered saline (PBS), pH 7.4 (Figure 2). These values are red-shifted from the respective maxima for Aad at $422 \mathrm{~nm}$ and $530 \mathrm{~nm}$. There is also a second Dad emission peak seen between 450 and $500 \mathrm{~nm}$ which comes from a protonated species (see below). The extinction coefficients of the Dad and Aad chromophores (Dad' and Aad', Figure 4) were measured by serial dilution (Figure S1). For Dad, $\varepsilon_{425} 5415 \pm 59 \mathrm{M}^{-1} \bullet \mathrm{cm}^{-1}$, which is similar to the extinction coefficient of Aad at 425 $\mathrm{nm}\left(\varepsilon 4255409 \pm 64 \mathrm{M}^{-1} \bullet \mathrm{cm}^{-1}\right)$. An integrating sphere was used to measure QYs. The QYs of Dad and Aad are 0.25 and 0.10, respectively, in 50:50 $\mathrm{CH}_{3} \mathrm{CN} / \mathrm{PBS}$, making Dad 2.5-fold brighter than Aad (Table 1). The fluorescence lifetimes of Dad and Aad, measured by time correlated single photon counting (TCSPC), were similar ( $\tau\left(\right.$ Dad) $12.9 \mathrm{~ns}, \tau\left(\right.$ Aad) $11.8 \mathrm{~ns}$ ) in 50:50 $\mathrm{CH}_{3} \mathrm{CN} / \mathrm{PBS}$ (Table 2). In pure PBS, the lifetimes of both fluorophores are reduced ( $\tau(\mathrm{Dad}) 6.3 \mathrm{~ns}, \tau(\mathrm{Aad}) 6.7 \mathrm{~ns}$ ) to values significantly smaller than the lifetime of Acd, which is $14.7 \mathrm{~ns}$ in buffer. The increased brightness and red-shift in emission should make Dad a superior probe to Aad for in vitro biophysical studies as well as for imaging.
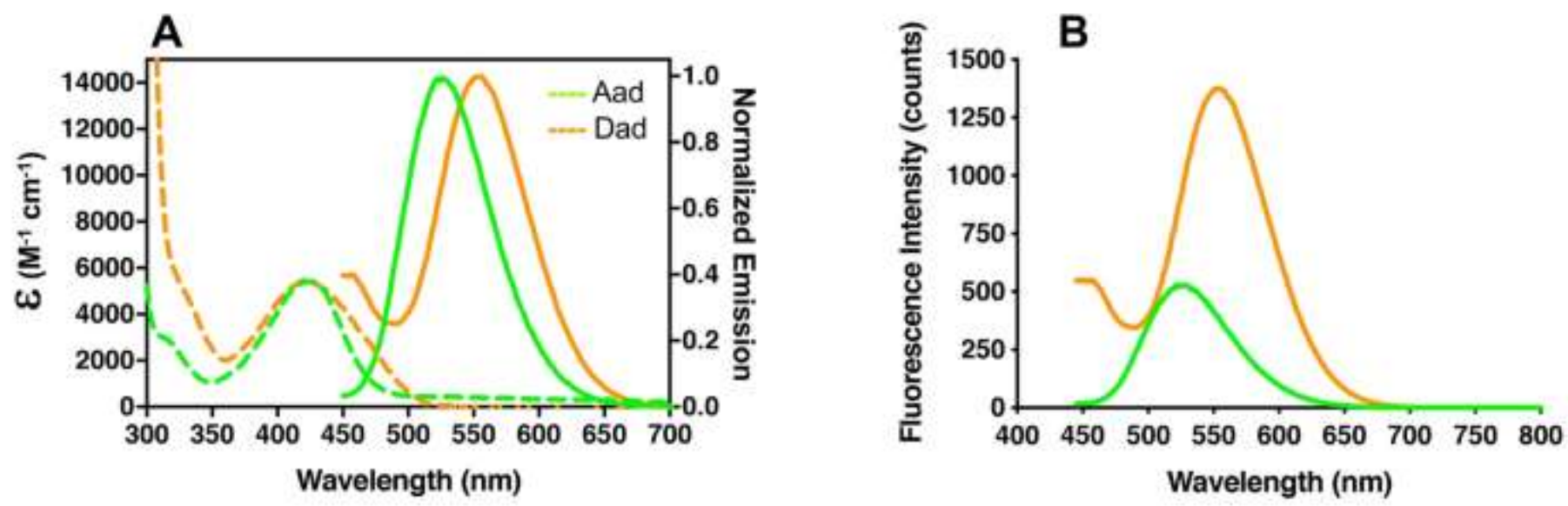

Figure 2. Comparison of Dad and Aad fluorescence properties. A) Comparison of excitation and emission for Aad and Dad in 50:50 $\mathrm{CH}_{3} \mathrm{CN} / \mathrm{PBS}(50 \mu \mathrm{M})$. The emission spectra have been normalized to show the red-shift in $\lambda_{\mathrm{Em}}$ clearly. B) Comparison of Aad and Dad emission in 50:50 $\mathrm{CH}_{3} \mathrm{CN} / \mathrm{PBS}(50 \mu \mathrm{M})$. ( $\left.\lambda_{\mathrm{Ex}} 425 \mathrm{~nm}\right)$. 
Acd and Aad are known to exhibit solvatochromic effects that primarily alter the QY, but have minor effects on the shape of the emission spectrum, with the exception that the Aad emission spectrum changes dramatically at low $\mathrm{pH}$, blue-shifting to resemble the Acd emission spectrum. This is because protonation of the amino group changes its hybridization to prevent it from extending the acridone $\pi$ system. Similarly, measurement of the Dad emission spectrum in 50:50 mixtures of acetonitrile with buffers of varying $\mathrm{pH}$ shows that the long wavelength emission disappears as the $\mathrm{pH}$ drops below 4, with double emission peaks at 405 and $420 \mathrm{~nm}$ like Acd and Aad at low pH (Figure 3 and Figure S2). In organic solvents, Dad emission also blue-shifts, although not as dramatically, with a maximum around $550 \mathrm{~nm}$ that varies only slightly in buffer, isopropanol, methanol, acetonitrile, and DMSO (Figure 3).
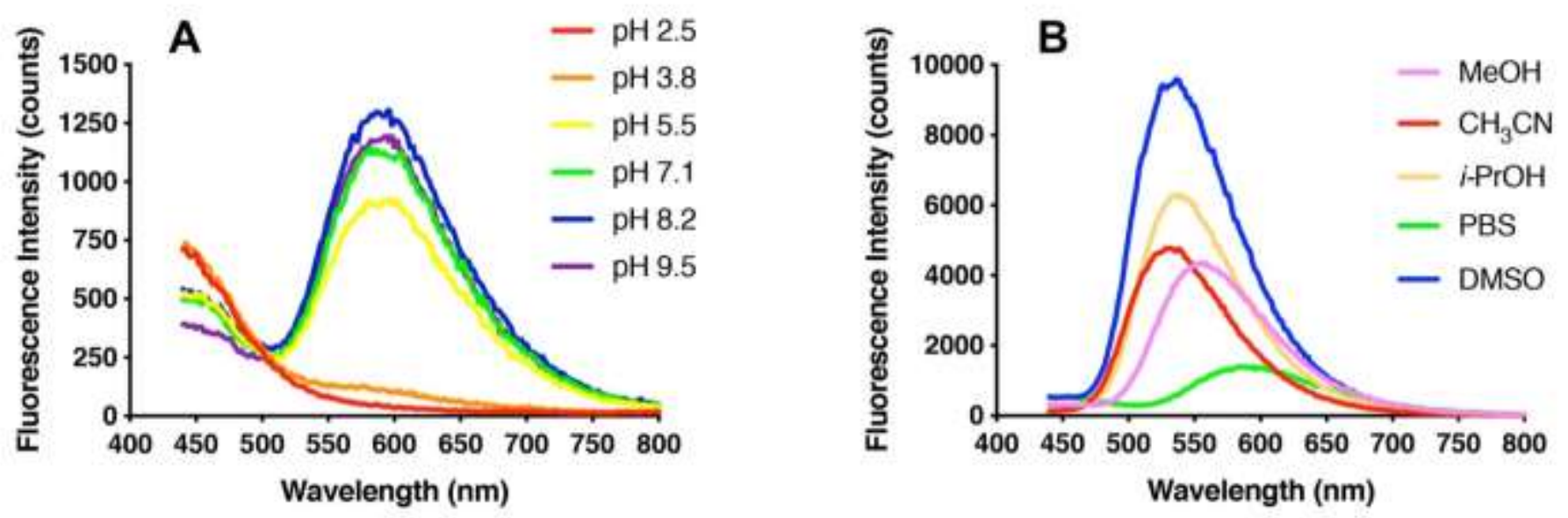

Figure 3. Solvent effects on Dad fluorescence. A. Emission spectra of $5 \mu \mathrm{M}$ Dad in CBTP buffer at various pHs ( $\left.\lambda_{\mathrm{Ex}} 425 \mathrm{~nm}\right)$. B. Emission spectra of $5 \mu \mathrm{M}$ Dad in various solvents $\left(\lambda_{\mathrm{Ex}} 425 \mathrm{~nm}\right)$.

Dad QY similarly varies in different solvents, reaching a maximum of 0.57 in DMSO. In all organic solvents, the Dad QY is higher than that of Aad (Table 1 and Figures S3-S4). The lifetime of Dad increases significantly in organic solvent relative to aqueous buffer, reaching a maximum of 19.91 ns in DMSO. In contrast, the lifetime of Aad in DMSO is 10.33 ns, although it is relatively similar to the lifetime of Dad in other solvents. These properties can be beneficial to Dad's applications as a biophysical probe, where changes in emission maximum, QY, or lifetime can be used to monitor changes in protein conformation that would place Dad in environments of different polarity and/or sequester it from water.

Table 1. QY (unitless) of Aad and Dad in various solvents*

\begin{tabular}{ccccccc}
\hline & DMSO & $\mathrm{MeOH}$ & $\mathrm{CH}_{3} \mathrm{CN}$ & $\mathrm{THF}$ & $\mathrm{PBS}$ & $\mathrm{CH}_{3} \mathrm{CN} / \mathrm{PBS}$ \\
\hline Dad & $0.57 \pm 0.08$ & $0.21 \pm 0.04$ & $0.24 \pm 0.03$ & $0.35 \pm 0.03$ & $0.06 \pm 0.01$ & $0.25 \pm 0.02$ \\
Aad & $0.12 \pm 0.01$ & $0.08 \pm 0.01$ & $0.09 \pm 0.01$ & $0.08 \pm 0.04$ & $0.05 \pm 0.01$ & $0.10 \pm 0.02$ \\
\hline
\end{tabular}

*QY determined using an integrating sphere as described in Supplementary Material.

The long lifetime of Dad in DMSO, nearly twice that of Aad, is surprising since the lifetimes of the two fluorophores are similar in other solvents (Table 2 and Figures S5-S7). We suspected that this could result from aggregation of Dad in DMSO, but we observed no concentration dependence as the Dad lifetime remains unchanged over a $10 \mathrm{nM}-1 \mathrm{mM}$ concentration range (Figure S6). Another possibility is that the viscosity of DMSO hinders rotation of the dimethylamino group in Dad, further reducing TICT to give Dad a longer lifetime 
and higher QY in DMSO. These phenomena are commonly observed in fluorophores for which bond rotation contributes to electronic excitation, including TICT processes involving dimethylamino groups. ${ }^{21,} 26-28$ While further investigation of the photophysical mechanism of this effect is warranted, we should be able to harness this effect to study conformational change in proteins based on placing Dad in a more sterically restricted environment.

Table 2. Fluorescence lifetime (in ns) of Aad and Dad in various solvents*

\begin{tabular}{ccccccc}
\hline & DMSO & $\mathrm{MeOH}$ & $\mathrm{CH}_{3} \mathrm{CN}$ & $\mathrm{THF}$ & $\mathrm{PBS}$ & $\mathrm{CH}_{3} \mathrm{CN} / \mathrm{PBS}$ \\
\hline Dad & $19.91 \pm 0.02$ & $12.64 \pm 0.02$ & $11.57 \pm 0.02$ & $12.85 \pm 0.01$ & $6.26 \pm 0.01$ & $12.92 \pm 0.06$ \\
Aad & $10.33 \pm 0.06$ & $10.83 \pm 0.03$ & $11.65 \pm 0.03$ & $11.59 \pm 0.04$ & $6.69 \pm 0.02$ & $11.82 \pm 0.04$ \\
\hline
\end{tabular}

*Details of fitting including decay curves and residuals as well as chi-squared metrics are reported in Supplementary Material.

Electronic structure calculations. We have previously performed $a b$ initio electronic structure calculations of the absorption and emission spectra for 11 acridone derivatives, including 2-aminoacridone (Aad', Figure 4), the parent chromophore of Aad. ${ }^{14}$ We saw an excellent correlation (an average difference of $2.4 \%$ for all absorption and emission maxima) between calculated and observed values across this series, so we here wished to apply the same computational methods to 2-(dimethylamino)acridone (Dad', Figure 4), the parent chromophore of Dad. The calculations were performed using Gaussian $16^{\mathrm{TM}}$ with an APF-D density functional and a 6-311+G(2d,p) basis set. ${ }^{29}$ The calculated vertical excitations and emissions for Dad' ( $\lambda_{\mathrm{Ex}} 436 \mathrm{~nm}, \lambda_{\mathrm{Ex}} 499 \mathrm{~nm}$ ) are at lower energy than the corresponding transitions for Aad' spectra ( $\lambda_{E x} 406 \mathrm{~nm}, \lambda_{E_{x}} 477 \mathrm{~nm}$ ), matching the experimental observations of a 20-30 nm red-shift in the maxima. In our previous study of acridone derivatives, we found that Franck-Condon integrals from vibrational calculations could be used to generate spectra that matched the experimental solution phase emission spectra extremely well. ${ }^{30}$ Unfortunately, in this case, we found that differences in the ground and excited state geometries of Dad prevented us from using the Franck-Condon strategy for Dad'. Therefore, we used the differences in the Dad' and Aad' vertical transitions to shift the Aad' vibronic emission spectrum to approximate the Dad' spectrum in water, matching the $50: 50 \mathrm{CH}_{3} \mathrm{CN} / \mathrm{PBS}$ experimental data well (Figure 4). Examination of the highest occupied molecular orbital (HOMO) and lowest unoccupied molecular orbital (LUMO) for Aad' (Figure S8) and Dad' (Figure 4) shows that the relevant transition for both molecules occurs by a shift in electron density from the pendant amino group into the acridone ring system, supporting our hypothesis that modulating TICT will improve brightness for these fluorophores. The ability to accurately model the excitation and emission of Dad will be valuable to designing derivatives that further red-shift its emission or improve its brightness. 
<smiles>Nc1ccc2[nH]c3ccccc3c(=O)c2c1</smiles><smiles>CN(C)c1ccc2[nH]c3ccccc3c(=O)c2c1</smiles>

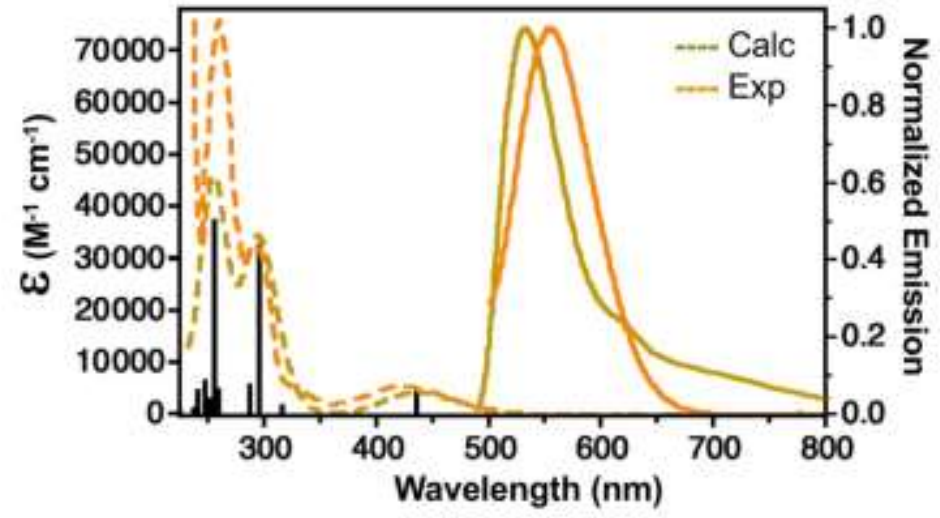

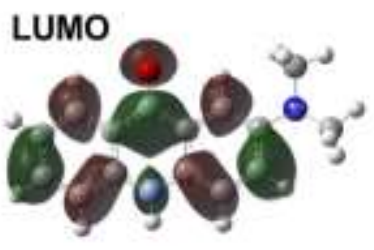

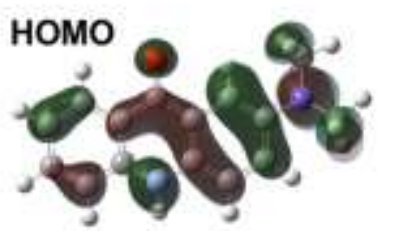

Figure 4. Comparison of experimental and computed Dad spectra. Experimental absorption and emission spectra for Dad were determined in 50:50 $\mathrm{CH}_{3} \mathrm{CN} / \mathrm{PBS}$. Computed spectra were determined from Dad' APF-D/6$311+G(2 d, p)$ vertical excitation and emission calculations and the shifted Aad' vibronic emission spectrum. Excitation spectra are shown as dashed lines, emission spectra are shown as solid lines. Individual calculated state-to-state transitions are shown as black vertical lines.

Dad incorporation for future protein studies. While Dad can be readily incorporated into peptides in a Boc or fluorenylmethoxycarbonyl (Fmoc) protected form, our ultimate goal is to genetically incorporate Dad into proteins using Uaa mutagenesis, also known as amber suppression. This technique requires that an aaRS be evolved to specifically charge its cognate tRNA with the desired amino acid. The amino acid will then be incorporated into the growing protein chain in response to an amber (TAG) stop codon within the mRNA sequence. An initial screening method for potential aaRSs is to test whether they can charge the Uaa onto a tRNA for incorporation into super-folder green fluorescent protein (sfGFP) that contains an amber stop codon. Only successful incorporation will lead to full length sfGFP and therefore sfGFP fluorescence can be used as a readout for aaRS activation of the Uaa. We used three engineered aaRSs derived from Methanocaldococcus jannachii (Mj) tyrosyl tRNA synthetase which have been previously shown to incorporate Acd: A9, G2, and G11. ${ }^{13}$ G2 has also been shown to activate Aad. Our initial sfGFP assay results show little Dad incorporation by any of the aaRSs, with sfGFP fluorescence comparable to the negative control experiment with no amino acid added (Figure 5). In contrast, sfGPF expression using Acd is robust for all three aaRS, as expected. It should be noted that although Acd and Dad are both fluorescent amino acids, since they are excited at 385 and $425 \mathrm{~nm}$, respectively, they do not interfere with the SfGFP assay which uses excitation at $488 \mathrm{~nm}$. Thus, it appears additional engineering of aaRSs will be necessary to genetically incorporate Dad. 

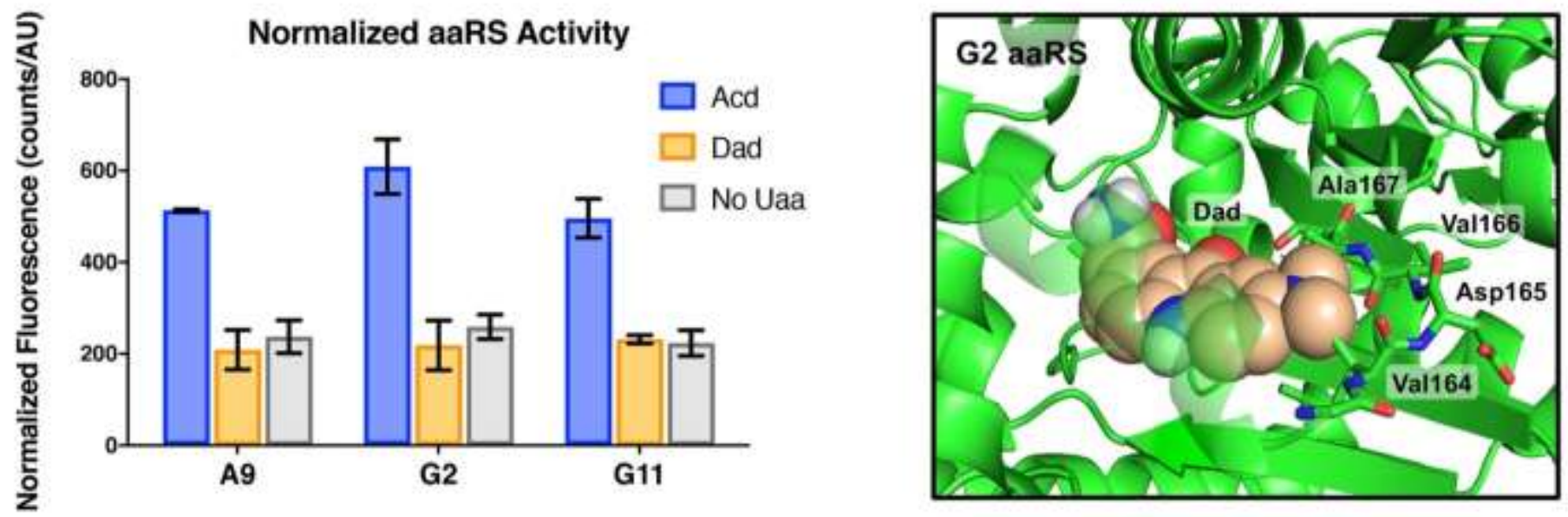

Figure 5. Prospects for genetic incorporation of Dad. Left: Incorporation efficiency of three $M j$ aaRS variants measured by sfGFP fluorescence intensity, normalized by cell density. None show significant Dad incorporation. Right: G2 aaRS active site structure (PDB ID: 4PBR) ${ }^{31}$ with Dad docked. Amino acids expected to interact with the dimethylamino group that are targets for mutation to improve Dad activity are highlighted.

Presumably the lack of aaRS activity toward Dad is a result of steric clashes with the dimethylamino group. Since a crystal structure is available for the $\mathrm{G} 2$ aaRS, ${ }^{31}$ and reliable homology models can be made for closely related mutants, computational modeling of Dad in the $\mathrm{G} 2$ active site can be used to identify the residues responsible for these clashes. ${ }^{13}$ Figure 5 shows Dad docked into the $\mathrm{G} 2$ aaRS active site by alignment to our previous model of docked Acd. Mutation of the highlighted residues Val164-Ala167, particularly Val164 and Ala167, could generate more permissive aaRSs to accommodate the additional steric bulk of Dad. ${ }^{13}$ These rationally designed efforts, as well as screening of random mutant libraries, are currently under way. If we can successfully generate an efficient aaRS for Dad, we will be able to easily incorporate it into proteins to take advantage of its utility as a small, green wavelength fluorophore for experiments like FP, as well as a potential FRET partner for Acd.

\section{Conclusions}

We were able to modulate the fluorescence of an acridone-based scaffold through simple alkylation, leading to the concise synthesis of a new fluorescent amino acid. Our synthetic route relied on preferentially methylating the 5-amino group of 2,5-aminobenzonitrile to form 2-amino-5-(dimethylamino)benzonitrile (1) before crosscoupling and cyclization to form Dad in $11 \%$ overall yield. The alkylated Dad has a higher QY and longer fluorescence lifetime than Aad, increasing its value for biophysical studies like FRET and FP as well as for imaging studies. Dad can be protected with a Boc or Fmoc group and incorporated into peptides using solid phase synthesis methods. Ultimately, we would like to genetically incorporate Dad and will work to obtain mutants of the $\mathrm{G} 2$ aaRS that can charge Dad onto tRNA in order to express Dad-labeled proteins in E. coli. For imaging applications, pyrolysyl aaRSs from archea can be evolved for incorporation of Uaas in both $E$. coli and mammalian cells, ${ }^{32}$ and efforts are underway in our laboratory to engineer these aaRSs to activate Acd, Aad, and Dad. 


\section{Experimental Section}

Synthesis of 2-amino-5-(dimethylamino)benzonitrile (1). 2,5 diaminobenzonitrile (500 mg, $3.78 \mathrm{mmol}, 1$ equiv.) and paraformaldehyde ( $284 \mathrm{mg} 9.46 \mathrm{mmol}, 2.5$ equiv.) were stirred in glacial acetic acid ( $250 \mathrm{~mL}$ degassed with argon) for fifteen minutes. Sodium cyanoborohydride (713 mg, $11.35 \mathrm{mmol}, 3$ equiv.) was added to the reaction mixture and stirred at room temperature under argon atmosphere for approximately 16 hours. The reaction was quenched in an ice bath by adding $10 \mathrm{M}$ sodium hydroxide dropwise until the mixture reached a pH of 6 . This can also be seen as a color change from pink/orange to yellow. The crude material was extracted with ethyl acetate, washed with $0.1 \mathrm{M}$ sodium hydroxide, dried with $\mathrm{Na}_{2} \mathrm{SO}_{4}$, and concentrated in vacuo. The single, double, and triply methylated species could not be distinguished using normal phase thin layer chromatography (TLC) and were instead followed by liquid chromatography-mass spectrometry (LC-MS). The crude mixture was purified by reverse phase chromatography ( $5 \%$ to $100 \%$ water with $0.1 \%$ TFA) in acetonitrile with $0.1 \%$ TFA. Pure fractions were collected and dried via lyophilization to yield the compound (302 $\mathrm{mg}, 49 \%$ yield). HRMS (ESI) calculated for $\mathrm{C}_{9} \mathrm{H}_{11} \mathrm{~N}_{3}{ }^{+}$is $161.1031,[\mathrm{M}+\mathrm{H}]$ found $162.1059 .{ }^{1} \mathrm{H} \mathrm{NMR}\left(500 \mathrm{MHz}, \mathrm{CD}_{3} \mathrm{OH}\right) \delta 7.02(\mathrm{~d}, J 9.2 \mathrm{~Hz}$, $1 \mathrm{H}), 6.79(\mathrm{~m}, 2 \mathrm{H}), 4.58(\mathrm{~s}, 1 \mathrm{H}), 2.79(\mathrm{~S}, 6 \mathrm{H}) .{ }^{13} \mathrm{C} \mathrm{NMR}\left(151 \mathrm{MHz}, \mathrm{CD}_{3} \mathrm{OH}\right) \delta_{c} 150.65,133.01,125.30,123.23$, $116.12,94.64,45.03$

Synthesis of methyl (S)-2-((tert-butoxycarbonyl)amino)-3-(4-((2-cyano-4-(dimethylamino)phenyl)amino) phenyl)propanoate (3). 2-amino-5-(dimethylamino)benzonitrile (1) (250 mg, $1.55 \mathrm{mmol}, 1.5$ equiv.) and methyl 2-((tert-butoxycarbonyl)amino)-3-(4-(((trifluoromethyl)sulfonyl)oxy)phenyl)propanoate (2) (440 $\mathrm{mg}, 1.03$ mmol, 1 equiv.) were combined with BrettPhos Pd G1 (methyl $t$-Butyl ether adduct, $82 \mathrm{mg}, 0.103 \mathrm{mmol}, 0.1$ equiv.) and cesium carbonate (1.010 g, $3.101 \mathrm{mmol}, 3$ equiv) in $8 \mathrm{~mL}$ of degassed dioxanes in a sealed round bottom flask. The flask was sparged and purged three times with argon, sealed and heated at $100{ }^{\circ} \mathrm{C}$ for roughly 24 hours. After the solution was cooled to room temperature, the contents were filtered through a short plug of silica gel using $\mathrm{CH}_{2} \mathrm{Cl}_{2}$ to transfer the material to the silica $(10 \mathrm{~mL})$, and then ethyl acetate $(60 \mathrm{~mL})$ was used to elute the product. The clarified solution was concentrated under reduced pressure and further purified by reverse phase chromatography ( $5 \%$ to $100 \%$ water in acetonitrile with $0.1 \%$ TFA). Pure fractions were collected and dried via lyophilization to yield the compound (256 mg, 46\%). HRMS (ESI) calculated for $\mathrm{C}_{24} \mathrm{H}_{30} \mathrm{~N}_{4} \mathrm{O}_{4}{ }^{+}$is 438.2345, $[\mathrm{M}+\mathrm{H}]$ found 439.2359. ${ }^{1} \mathrm{H}$ NMR $\left(500 \mathrm{MHz}, \mathrm{CD}_{3} \mathrm{OH}\right) \delta 7.20(\mathrm{~d}, J 9.1 \mathrm{~Hz}, 1 \mathrm{H}), 7.10-6.98(\mathrm{~m}, 3 \mathrm{H}), 6.93$ (d, J $3.0 \mathrm{~Hz}, 1 \mathrm{H}), 6.88-6.75(\mathrm{~m}, 2 \mathrm{H}), 4.31(\mathrm{t}, J 8.5,5.7 \mathrm{~Hz}, 1 \mathrm{H}), 3.68(\mathrm{~s}, 2 \mathrm{H}), 3.35(\mathrm{~s}, 1 \mathrm{H}), 2.99(\mathrm{dd}, J 13.8,5.8 \mathrm{~Hz}$, $1 \mathrm{H}), 2.92(\mathrm{~s}, 6 \mathrm{H}), 2.83(\mathrm{dd}, J$ 14.0, $8.6 \mathrm{~Hz}, 1 \mathrm{H}), 1.40(\mathrm{~s}, 9 \mathrm{H}) .{ }^{13} \mathrm{C} N M R\left(151 \mathrm{MHz}, \mathrm{CDCl}_{3}\right) \delta \mathrm{C}: 172.49,155.12,137.89$, $133.24,129.30,127.90,125.60,123.24,122.40,121.35,116.10,115.92,114.00,99.03,80.18,54.57,52.24$, $37.53,29.72$

Synthesis of methyl (S)-2-((tert-butoxycarbonyl)amino)-3-(7-(dimethylamino)-9-oxo-9,10-dihydroacridin-2yl)propanoate (Dad, 4): A solution of $13.5 \mathrm{M}(6 \mathrm{~mL})$ sulfuric acid was added to a flask containing $(S)-2-(($ tertbutoxycarbonyl)amino)-3-(4-((2-cyano-4-(dimethylamino)phenyl)amino)phenyl)propanoate (3) (250 mg, 0.570 mmol, 1 equiv.). The flask was refluxed at $115^{\circ} \mathrm{C}$ with vigorous stirring for approximately 24 hours. The solution was cooled to room temperature and quenched using $25 \mathrm{~mL}$ of cold water, added dropwise. The $\mathrm{pH}$ was adjusted to 7 using $10 \mathrm{M} \mathrm{NaOH}$. The resulting precipitate was collected using vacuum filtration and purified using reverse phase chromatography ( $5 \%$ to $100 \%$ Water $(0.1 \%$ TFA) in Acetonitrile $(0.1 \%$ TFA)). Pure fractions were collected and dried via lyophilization to yield the desired product ( $96 \mathrm{mg}, 52 \%$ ). HRMS (ESI) calculated for $\mathrm{C}_{18} \mathrm{H}_{19} \mathrm{~N}_{3} \mathrm{O}_{3}{ }^{+}$is $325.1505,[\mathrm{M}+\mathrm{H}]$ found 326.1516. ${ }^{1} \mathrm{H} \mathrm{NMR}\left(500 \mathrm{MHz}, \mathrm{CD}_{3} \mathrm{OH}\right) \delta_{\mathrm{H}} 8.40(\mathrm{~s}, 1 \mathrm{H}), 7.84(\mathrm{dd}, J=8.8$, $1.9 \mathrm{~Hz}, 1 \mathrm{H}), 7.82-7.74(\mathrm{~m}, 3 \mathrm{H}), 7.35(\mathrm{~s}, 1 \mathrm{H}), 4.39(\mathrm{dd}, J=7.8,6.1 \mathrm{~Hz}, 1 \mathrm{H}), 3.54(\mathrm{dd}, J=14.7,6.1 \mathrm{~Hz}, 1 \mathrm{H}), 3.38$ (dd, $J=14.6,7.8 \mathrm{~Hz}, 1 \mathrm{H}), 3.15(\mathrm{~s}, 6 \mathrm{H}) .{ }^{13} \mathrm{C} N M R\left(151 \mathrm{MHz}, \mathrm{CD}_{3} \mathrm{OH}\right) \delta_{\mathrm{C}} 170.93,155.48,147.91,137.32,135.25$, $132.43,131.07,125.31,123.89,119.35,119.00,113.47,111.10,99.72,54.79,39.49,36.31$. 
Absorbance Measurements. Dad was dissolved in MilliQ water and $100 \mathrm{uL}$ of $2 \mathrm{M}$ sodium hydroxide to make a to a $5 \mathrm{mM}$ starting stock. Samples were individually diluted to the desired concentration using 50:50 acetonitrile to phosphate buffered saline $\left(\mathrm{CH}_{3} \mathrm{CN} / \mathrm{PBS}\right)$ in triplicate. The absorbance spectrum was measured on a ThermoScientific Genesys 150 UV-Vis spectrometer, using 50:50 $\mathrm{CH}_{3} \mathrm{CN} / \mathrm{PBS}$ as a blank. These absorbances were also measured using a Tecan M1000 plate reader with acridone as a standard.

Fluorescence Measurements. Fluorescence measurements were performed on $5 \mu \mathrm{M}$ samples on either a Tecan

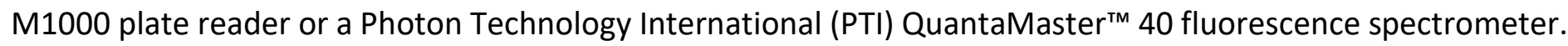
The $\mathrm{pH}$ dependent measurements were performed $50 / 50 \mathrm{CH}_{3} \mathrm{CN}$ neutralized in alumina/citric acid BIS-TRIS propane (CBTP) buffer. The buffer system relies of varying ratios of citric acid to BIS-TRIS propane to achieve buffers with predictable $\mathrm{pH}$ 's. The $\mathrm{pH}$ for each buffer $/ \mathrm{CH}_{3} \mathrm{CN}$ mixture was confirmed using a $\mathrm{pH}$ meter. Fluorescence lifetime measurements were collected using the QuantaMaster ${ }^{\mathrm{TM}} 40$ TCSPC module with a $486 \mathrm{~nm}$ pulsed LED light source. QY measurements were performed using a Jasco FP-8300 fluorimeter with an ILF-835 integrating sphere attachment.

Quantum Mechanical Calculations. Ab initio electronic structure calculations of the absorption and emission spectra of Aad' and Dad' employed the APF-D density functional as implemented in the Gaussian $16^{\mathrm{TM}}$ suite of programs with the $6-311+G(2 d, p)$ basis set which has been recommended for calculations of fluorescence spectra. ${ }^{29}$ Using a previously described procedure, ${ }^{30}$ we combined Franck-Condon integral calculations with vibrational calculations of the ground and first excited states to generate vibronic spectra representing Aad' absorption and emission spectra in aqueous solution. The differences in the lowest energy Aad' and Dad' vertical transitions were used to shift the Aad' emission spectrum to approximate the Dad' spectrum.

Dad aaRS Activity Assay. BL21-DE3 E. coli cells were transformed with a pBad plasmid encoding superfolder GFP

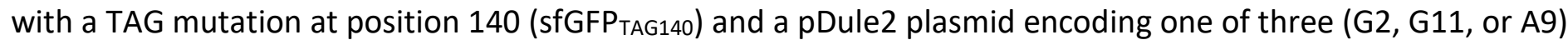
previously evolved $\mathrm{Mj}$ tyrosine aaRSs. ${ }^{13}$ Cells were grown with ampicillin (Amp, $100 \mu \mathrm{g} / \mathrm{mL}$ ) and streptomycin (Strep, $50 \mu \mathrm{g} / \mathrm{mL}$ ) on an LB-agar plate. As a negative control, BL21-DE3 E. coli cells were transformed with only the sfGFPTAG140 plasmid, and grown with only ampicillin (Amp, $100 \mu \mathrm{g} / \mathrm{mL}$ ) in parallel to the doubly transformed cells. Single colonies were picked and grown in non-inducing media ${ }^{33}(1 \times 5 \mathrm{~mL}, 100 \mu \mathrm{g} / \mathrm{mL} \mathrm{Amp,} 50 \mu \mathrm{g} / \mathrm{mL}$ ) with shaking ( $250 \mathrm{RPM}$ ) at $37^{\circ} \mathrm{C}$ until saturation. $5 \%$ of each primary culture was added to a $2 \mathrm{~mL}$ secondary culture in auto-inducing media ${ }^{33}$ that contained either $1 \mathrm{mM}$ Acd (positive control), $1 \mathrm{mM}$ Dad, or no fluorescent amino acid (negative control). Each secondary culture was split into $3 \times 1 \mathrm{~mL}$ triplicate cultures and incubated with shaking ( $250 \mathrm{RPM}$ ) at $37^{\circ} \mathrm{C}$ for 24 hours. Each culture was diluted 10-fold with MilliQ water and the sfGFP fluorescence intensity was quantified ( $\lambda_{\text {ex }}: 488 \mathrm{~nm}, \lambda_{\mathrm{em}}: 509 \mathrm{~nm}$ ). Additionally, the optical density was measured at $600 \mathrm{nM}\left(\mathrm{OD}_{600}\right)$ to normalize the fluorescence reading to the number of cells.

Dad Docking Model. Using PyMol, ${ }^{34}$ the optimized ground state structure of Dad' was aligned with the sidechain of Acd docked into a homology model of the G2 aaRS built using the crystal structure coordinates, as previously described. ${ }^{13,30-31}$ The Dad' molecule was aligned to position the dimethylamino group as in Dad.

\section{Acknowledgements}

This work was supported by funding from the National Science Foundation (NSF CHE-1150351 to E.J.P.) and includes calculations carried out on Temple University's HPC resources (supported by NSF MRI-1625061 and by U.S. Army Research Laboratory contract W911NF-16-2-0189). Instruments supported by the NSF and National Institutes of Health include: NMR (NSF CHE-1827457), HRMS (NIH RR-023444), and computers (NIH S10 OD- 
023592). C.M.J. thanks the NIH for funding through the Structural Biology and Molecular Biophysics Training Program (T32 GM-008275).

\section{Supplementary Material}

Copies of ${ }^{1} \mathrm{H}$ and ${ }^{13} \mathrm{C}$ NMR spectra, additional absorbance and fluorescence data including details of extinction coefficient, QY and lifetime determination, and protocols for biological assays and calculations can be found in the supplementary material file.

\section{References}

1. Jun, J. V.; Chenoweth, D. M.; Petersson, E. J., Org. Biomol. Chem. 2020, 18, 5747-5763. http://dx.doi.org/10.1039/D0OB01131B

2. Lavis, L. D.; Raines, R. T., ACS Chem. Biol. 2014, 9, 855-866. http://dx.doi.org/10.1021/cb500078u

3. Lavis, L. D.; Raines, R. T., ACS Chem. Biol. 2008, 3, 142-155. http://dx.doi.org/10.1021/cb700248m

4. Speight, L. C.; Samanta, M.; Petersson, E. J., Aust. J. Chem. 2014, 67, 686-700. http://dx.doi.org/10.1071/CH13554

5. Haney, C. M.; Wissner, R. F.; Petersson, E. J., Curr. Opin. Chem. Biol. 2015, 28, 123-130. http://dx.doi.org/10.1016/i.cbpa.2015.07.007

6. Cheng, Z.; Kuru, E.; Sachdeva, A.; Vendrell, M., Nat. Rev. Chem. 2020, 4, 275-290. http://dx.doi.org/10.1038/s41570-020-0186-z

7. Park, S.-H.; Raines, R. T., Fluorescence Polarization Assay to Quantify Protein-Protein Interactions. In Protein-Protein Interactions: Methods and Applications, Fu, H., Ed. Humana Press: Totowa, NJ, 2004; 161165.

http://dx.doi.org/10.1385/1-59259-762-9:161

8. Raines, R. T., Fluorescence Polarization Assay to Quantify Protein-Protein Interactions: An Update. In Protein-Protein Interactions: Methods and Applications, Meyerkord, C. L.; Fu, H., Eds. Springer New York: New York, NY, 2015; 323-327. http://dx.doi.org/10.1007/978-1-4939-2425-7 19

9. Loving, G. S.; Sainlos, M.; Imperiali, B., Trends Biotechnol. 2010, 28, 73-83. http://dx.doi.org/10.1016/j.tibtech.2009.11.002

10. Schuler, B.; Hofmann, H., Curr. Opin. Struct. Biol. 2013, 23, 36-47. https://doi.org/10.1016/i.sbi.2012.10.008

11. Speight, L. C.; Muthusamy, A. K.; Goldberg, J. M.; Warner, J. B.; Wissner, R. F.; Willi, T. S.; Woodman, B. F.; Mehl, R. A.; Petersson, E. J., J. Am. Chem. Soc. 2013, 135, 18806-18814. http://dx.doi.org/10.1021/ja403247i

12. Ferrie, J. J.; leda, N.; Haney, C. M.; Walters, C. R.; Sungwienwong, I.; Yoon, J.; Petersson, E. J., Chem. Commun. 2017, 53, 11072-11075. http://dx.doi.org/10.1039/C7CC05492K 
13. Sungwienwong, I.; Hostetler, Z. M.; Blizzard, R. J.; Porter, J. J.; Driggers, C. M.; Mbengi, L. Z.; Villegas, J. A.; Speight, L. C.; Saven, J. G.; Perona, J. J.; Kohli, R. M.; Mehl, R. A.; Petersson, E. J., Org. Biomol. Chem. 2017, 15, 3603-3610.

http://dx.doi.org/10.1039/C70B00582B

14. Hostetler, Z. M.; Ferrie, J. J.; Bornstein, M. R.; Sungwienwong, I.; Petersson, E. J.; Kohli, R. M., ACS Chem. Biol. 2018, 13, 2855-2861.

http://dx.doi.org/10.1021/acschembio.8b00696

15. Hostetler, Z. M.; Cory, M. B.; Jones, C. M.; Petersson, E. J.; Kohli, R. M., ACS Chem. Biol. 2020, 15, 11271133.

http://dx.doi.org/10.1021/acschembio.9b00886

16. Padmanarayana, M.; Hams, N.; Speight, L. C.; Petersson, E. J.; Mehl, R. A.; Johnson, C. P., Biochemistry 2014, 53, 5023-5033.

http://dx.doi.org/10.1021/bi5004469

17. Batjargal, S.; Walters, C. R.; Petersson, E. J., J. Am. Chem. Soc. 2015, 137, 1734-1737.

http://dx.doi.org/10.1021/ja5103019

18. Huang, Y.; Ferrie, J. J.; Chen, X.; Zhang, Y.; Szantai-Kis, D. M.; Chenoweth, D. M.; Petersson, E. J., Chem. Commun. 2016, 52, 7798-7801. http://dx.doi.org/10.1039/C6CC00105J

19. Pope, A. J.; Haupts, U. M.; Moore, K. J., Drug Disc. Today 1999, 4, 350-362. https://doi.org/10.1016/S1359-6446(99)01340-9

20. Lakowicz, J. R., Principles of Fluorescence Spectroscopy. Springer: 2006. http://dx.doi.org/10.1007/978-0-387-46312-4

21. Grabowski, Z. R.; Rotkiewicz, K.; Rettig, W., Chem. Rev. 2003, 103, 3899-4032. http://dx.doi.org/10.1021/cr940745I

22. Grimm, J. B.; English, B. P.; Chen, J.; Slaughter, J. P.; Zhang, Z.; Revyakin, A.; Patel, R.; Macklin, J. J.; Normanno, D.; Singer, R. H.; Lionnet, T.; Lavis, L. D., Nat. Methods 2015, 12, 244-250. http://dx.doi.org/10.1038/nmeth.3256

23. Vogel, M.; Rettig, W.; Sens, R.; Drexhage, K. H., Chem. Phys. Lett. 1988, 147, 452-460. https://doi.org/10.1016/0009-2614(88)85007-3

24. Harris, N. V.; Smith, C.; Bowden, K., Eur. J. Med. Chem. 1992, 27, 7-18. https://doi.org/10.1016/0223-5234(92)90054-5

25. Jones, C. M.; Venkatesh, Y.; Petersson, E. J., Chapter Three - Protein Labeling for Fret with Methoxycoumarin and Acridonylalanine. In Methods Enzymol., Chenoweth, D. M., Ed. Academic Press: 2020; Vol. 639, 37-69. https://doi.org/10.1016/bs.mie.2020.04.008

26. Loutfy, R. O.; Arnold, B. A., J. Phys. Chem. 1982, 86, 4205-4211. http://dx.doi.org/10.1021/j100218a023

27. Saha, S. K.; Purkayastha, P.; Das, A. B.; Dhara, S., J. Photochem. Photobiol. A 2008, 199, 179-187. https://doi.org/10.1016/i.jphotochem.2008.05.020

28. Dey, J.; Warner, I. M., J. Phys. Chem. A 1997, 101, 4872-4878. http://dx.doi.org/10.1021/ip9638696

29. Frisch, M. J.; Trucks, G. W.; Schlegel, H. B.; Scuseria, G. E.; Robb, M. A.; Cheeseman, J. R.; Scalmani, G.; Barone, V.; Petersson, G. A.; Nakatsuji, H.; Li, X.; Caricato, M.; Marenich, A. V.; Bloino, J.; Janesko, B. G.; Gomperts, R.; Mennucci, B.; Hratchian, H. P.; Ortiz, J. V.; Izmaylov, A. F.; Sonnenberg, J. L.; Williams-Young, 
D.; Ding, F.; Lipparini, F.; Egidi, F.; Goings, J.; Peng, B.; Petrone, A.; Henderson, T.; Ranasinghe, D.; Zakrzewski, V. G.; Gao, J.; Rega, N.; Zheng, G.; Liang, W.; Hada, M.; Ehara, M.; Toyota, K.; Fukuda, R.; Hasegawa, J.; Ishida, M.; Nakajima, T.; Honda, Y.; Kitao, O.; Nakai, H.; Vreven, T.; Throssell, K.; J. A. Montgomery, J.; Peralta, J. E.; Ogliaro, F.; Bearpark, M. J.; Heyd, J. J.; Brothers, E. N.; Kudin, K. N.; Staroverov, V. N.; Keith, T. A.; Kobayashi, R.; Normand, J.; Raghavachari, K.; Rendell, A. P.; Burant, J. C.; Iyengar, S. S.; Tomasi, J.; Cossi, M.; Millam, J. M.; Klene, M.; Adamo, C.; Cammi, R.; Ochterski, J. W.; Martin, R. L.; Morokuma, K.; Farkas, O.; Foresman, J. B.; Fox, D. J., Gaussian 16, Revision A.03. Gaussian, Inc.: Wallingford CT, 2016.

30. Sungwienwong, I.; Ferrie, J. J.; Jun, J. V.; Liu, C.; Barrett, T. M.; Hostetler, Z. M.; leda, N.; Hendricks, A.; Muthusamy, A. K.; Kohli, R. M.; Chenoweth, D. M.; Petersson, G. A.; Petersson, E. J., J. Phys. Org. Chem. 2018, 31, e3813.

http://dx.doi.org/10.1002/poc.3813

31. Cooley, R. B.; Karplus, P. A.; Mehl, R. A., ChemBioChem 2014, 15, 1810-1819. http://dx.doi.org/10.1002/cbic.201402180

32. Chin, J. W., Nature 2017, 550, 53-60. http://dx.doi.org/10.1038/nature24031

33. Hammill, J. T.; Miyake-Stoner, S.; Hazen, J. L.; Jackson, J. C.; Mehl, R. A., Nat. Protocols 2007, 2, $2601-2607$. http://dx.doi.org/10.1038/nprot.2007.379

34. Schrödinger The Pymol Molecular Graphics System, Version 1.3, 2015. 